\title{
UV-curable low-surface-energy fluorinated poly(urethane-acrylate)s for biomedical applications
}

\author{
Y.H. Lin ${ }^{a}$, K.H. Liao ${ }^{b}$, N.K. Chou ${ }^{c}$, S.S. Wang ${ }^{c}$, S.H. Chu ${ }^{\text {c,d }}$, K.H. Hsieh ${ }^{\text {a,b,* }}$ \\ ${ }^{a}$ Department of Chemical Engineering, National Taiwan University, Taipei, Taiwan \\ ${ }^{\mathrm{b}}$ Institute of Polymer Science and Engineering, National Taiwan University, Taipei, Taiwan \\ ${ }^{\mathrm{c}}$ Department of Surgery, College of Medicine, National Taiwan University Hospital, Taipei, Taiwan \\ ${ }^{\mathrm{d}}$ Department of Cardiovascular Surgery, Far Eastern Memorial Hospital, Taipei, Taiwan
}

\section{A R T I C L E I N F O}

\section{Article history:}

Received 28 April 2008

Received in revised form 19 June 2008

Accepted 21 June 2008

Available online 1 July 2008

\section{Keywords:}

UV-curable

Low-surface-energy

Fluorinated

Poly(urethane-acrylate)

Phase separation

Blood compatibility

\begin{abstract}
A B S T R A C T
Novel UV-curable fluorinated poly(urethane-acrylate) (FPUA) oligomers have been synthesized from $1 H, 1 H, 12 H, 12 H$-perfluoro-1,12-dodecanediol (PFDDOL), either 1,6-hexamethylene diisocyanate (HDI) or 4,4'-diphenylmethane diisocyanate (MDI), and 2-hydroxyethyl methacrylate (HEMA) for end-capping with photo-crosslinkable methacrylate groups. The fluorine content and the nature of the isocyanate were investigated to determine their effects on the physical properties, surface properties, and blood compatibilities of the polymers. The introduction of hydrophobic fluorocarbon chains led to phase separation and a low total surface energy, which reduced the adhesion of blood platelets onto the materials. The HDI-type UV-curable, fluorinated poly(urethane-acrylate) exhibited a low-surfaceenergy and superior blood compatibility (as determined from RIPA values).
\end{abstract}

(C) 2008 Elsevier Ltd. All rights reserved.

\section{Introduction}

An important factor in the development of medical devices is their blood compatibility. Studies aimed at improving blood compatibility have resulted [1] in several polymer surfaces exhibiting good blood compatibility, e.g., surfaces composed of non-ionic hydrophilic polymers [2-4] and microphase separated domains [5,6].

Segmented polyurethanes are generally constructed from di- or trifunctional isocyanate groups that react with polyols under step-growth polymerization conditions with diols or diamines acting as chain extenders. Using this approach, the properties of the polyurethanes can be manipulated by varying the nature of the polyols, isocyanates, and chain extenders. For polyurethanes to be applied

\footnotetext{
* Corresponding author. Address: Department of Chemical Engineering, National Taiwan University, Taipei, Taiwan. Tel.: +886 23366 5314; fax: +886223627688.

E-mail address: khhsieh@ntu.edu.tw (K.H. Hsieh).
}

extensively as biomaterials, they must exhibit good elasticity and high tensile strength, elongation, and blood compatibility [7-9]. Polyurethanes are frequently used in artificial hearts, vascular prostheses, and many types of catheters in various clinical applications. Hydrophilic/ hydrophobic microdomain structures, such as those of polyurethane, generally display higher blood compatibility $[10,11]$. Grasel and Cooper reported that materials exhibiting a greater amount of phase separation had low platelet and fibrinogen deposition levels [12]. In addition to the domain structure, many other factors - including the surface chemistry, hydrophilicity, and roughness - influence the degree of protein adsorption, biocompatibility, cellular growth, and platelet activation [13-15].

The use of fluorinated monomers and oligomers for coatings is very attractive because of the peculiar characteristics provided by the presence of fluorine atoms: hydrophobicity, chemical stability, weathering resistance, good release properties, low coefficients of friction, water impermeability, and low refractive indices. Several 
fluorinated monomers are presently used for many coating applications [16,17]. Fluorodiol-containing polyurethanes have attracted interest as surface-modifying agents because of their low surface energies $[18,19]$ and high biocompatibilities $[20,21]$. In particular, fluorocarbon chains have been incorporated into polyurethanes via fluorinecontaining diisocyanates [22], chain extenders [21,22$25]$, and soft segments $[20,22,26,27]$. For instance, Ratner et al. [21,23] synthesized a series of fluorine-containing aromatic polyurethanes from various perfluoro chain extenders and studied their surface and bulk structures. Kajiyama et al. [24] introduced a fluorocarbon-containing diol as a chain extender into a polyurethane and examined its effect on the resulting surface properties. Santerre et al. [28] used fluorine-containing polyurethanes, used as surface-modifying macromolecules, to alter the surface chemistry of base polyurethanes, thereby changing their biostability and/or biocompatibility. A number of studies have found that prostheses treated with fluorodiol-containing film deposits offer dramatic improvements in terms of resistance to the formation of thrombi and emboli $[20,29]$. When fluorine-containing diols are used as chain extenders in polyurethanes, the greater content of fluorine atoms present on the surface results in materials that are more thromboresistant $[30,31]$.

Photopolymerization processes are of great interest in industrial applications because solvent-free formulations are often characterized by higher production rates and energy efficiencies than are thermal systems. The advantages afforded by photopolymerization processes have led to rapid growth in their use in various fields, including the preparation of films and coatings on substrates such as paper, metal, plastic, and wood. Acrylate and methacrylate groups have been used widely for UV photopolymerization because their high reactivities [32] lead to rapid, nearcomplete conversions, i.e. no residual unreacted monomers, with control of the evolution of the heat of polymerization. UV-photopolymerized poly( $\varepsilon$-caprolactone-co-lactide-co-glycolide) diacrylate also produced a biodegradable network with potential for scaffolding applications [33]. Ward et al. [34] employed various polymers in the modified microfabrication-based UV photopolymerization to produce regions exhibiting distinct physical and chemical properties. Bongiovanni et al. synthesized numerous fluoro additives in UV-curable epoxy $[35,36]$, vinyl ether [37], and oxetane [38,39] systems to increase the hydrophobicity of film surfaces. We became interested in employing fluorinated structures in UV-curable poly(urethane-acrylate) systems.

In this paper we report the synthesis and characterization of novel UV-curable fluorinated poly(urethane-acrylate) (FPUA) oligomers prepared from $1 \mathrm{H}, 1 \mathrm{H}, 12 \mathrm{H}$, 12H-perfluoro-1,12-dodecanediol (PFDDOL) and either 1,6-hexamethylene diisocyanate (HDI) or 4,4'-diphenylmethane diisocyanate (MDI), and end-capped with photocrosslinkable methacrylate groups. The hydrophilic (HEMA and urethane groups)/hydrophobic (PFDDOL) domain-separated structure affected the surface tension, resulting in the formation of hydrophilic and hydrophobic domains within the fluorinated poly(urethane-acrylate)s. The presence of such domains reduced the adhesion of blood plate- lets onto these materials. We investigated the effects of the fluorine content and the nature of the isocyanate on the physical properties, surface properties, and blood compatibilities of these fluorinated poly(urethane-acrylate)s.

\section{Experimental}

\subsection{Materials}

1H,1H,12H,12H-Perfluoro-1,12-dodecanediol (PFDDOL; MW: $562 \mathrm{~g} \mathrm{~mol}^{-1}$; SynQuest Labs, USA) was dissolved in dry $N, N$-dimethylformamide (DMF, Aldrich). 4,4'-Diphenylmethane diisocyanate (MDI, TCI), 1,6-hexamethylene diisocyanate (HDI, Acros), 1,8-diazabicyclo[5.4.0]undec-7ene (DBU, Acros), 1-hydroxyclyclohexyl acetophenone (Irgacure 184, Ciba Special Chemicals), and tripropylene glycol diacrylate (TPGDA, AGI, Taiwan) were use as received. 2-Hydroxyethyl methacrylate (HEMA, Acros) and DMF were distilled under vacuum and dried over $4 \AA$ molecular sieves prior to use.

\subsection{Preparation of UV-curable fluorinated poly(urethane- acrylate) (FPUA) oligomers}

\subsubsection{MDI-type oligomer [40]}

The MDI-type FPUA oligomer based on PFDDOL, MDI, and HEMA was synthesized through two-step polymerization. In the first step, the prepolymer was synthesized from PFDDOL ( 0.01 mol equiv.) and MDI ( 0.02 mol equiv.) at an $[\mathrm{OH}] /[\mathrm{NCO}]$ ratio of $1: 2$ in a $100-\mathrm{mL}$, round-bottom, fourneck reaction flask equipped with a thermometer, a stirrer, and an inlet and outlet for dry nitrogen. The reaction was performed at $60^{\circ} \mathrm{C}$ under a dry nitrogen atmosphere. No catalyst was added. The reaction was monitored until the signal for free NCO groups (at $2270 \mathrm{~cm}^{-1}$ ) in the IR spectrum no longer decreased, a process that took ca. $2 \mathrm{~h}$. The prepolymer was then mixed with DMF until clarification. In the second step, HEMA ( $0.02 \mathrm{~mol}$ equiv.) was added to the mixture of the prepolymer to provide an $[\mathrm{OH}] /[\mathrm{NCO}]$ ratio of $1: 1$. The total solid content was $50 \mathrm{wt} \%$. Completion of the reaction was confirmed by the absence of a signal for free NCO groups at $2270 \mathrm{~cm}^{-1}$ in the IR spectrum, a process that took ca. $1 \mathrm{~h}$.

\subsubsection{HDI-type oligomer}

The HDI-type FPUA oligomer based on PFDDOL, HDI, and HEMA was synthesized through two-step polymerization. In the first step, the prepolymer was synthesized from PFDDOL (0.01 mol equiv.) and HDI (0.02 mol equiv.) at an $[\mathrm{OH}] /[\mathrm{NCO}]$ ratio of $1: 2$ in a $100-\mathrm{mL}$, round-bottom, fourneck reaction flask equipped with a thermometer, a stirrer, and an inlet and outlet for dry nitrogen. The reaction, which was conducted with $0.1 \mathrm{wt} \%$ DBU as the catalyst, was performed at $60^{\circ} \mathrm{C}$ under a dry nitrogen atmosphere and monitored until the signal for free NCO groups (at $2270 \mathrm{~cm}^{-1}$ ) in the IR spectrum no longer decreased, a process that took ca. $3 \mathrm{~h}$. The prepolymer was then mixed with DMF until clarification. In the second step, HEMA $(0.02 \mathrm{~mol}$ equiv.) was added to the mixture of the prepolymer. The total solid content was $50 \mathrm{wt} \%$. Completion of the reaction 
was confirmed by the absence of a signal for free NCO groups at $2270 \mathrm{~cm}^{-1}$ in the IR spectrum, a process that took ca. $12 \mathrm{~h}$. The reaction scheme for the synthesis of MDI-type and HDI-type FPUA oligomers are shown in Scheme 1.

\subsubsection{UV-curable FPUA films [33]}

The UV-curable FPUA was formulated from 3 wt\% photoinitiator (Irgacure 184), FPUA oligomer, and TPGDA monomer. The UV resin was sandwiched between two pieces of glass with a 1-mm-thick spacer and photopolymerized for $100 \mathrm{~s}$ using a flood UV exposure system equipped with a 350-W mercury lamp having an intensity at $365 \mathrm{~nm}$ of $330 \mathrm{~mJ} \mathrm{~cm}^{-2}$. The films were conditioned in a hood at room temperature for $24 \mathrm{~h}$. Table 1 lists the nomenclature and chemical composition of each of the materials prepared in this study. As an example of the nomenclature used herein, for the sample named $\mathrm{M}-25$, the letter refers to the diisocyanate type and the number indicates that the sample comprised $25 \mathrm{wt} \%$ FPUA oligomer and 75 wt\% TPGDA.

\subsubsection{Gel permeation chromatography (GPC)}

The GPC experiments were performed by passing a 0.2 wt\% tetrahydrofuran (THF, TEDIA) solution of the polymers through a Waters Associates chromatograph (model 6000A pump) equipped with three columns - one Polymer Laboratories Mixed-C and two American Polymer Standard 100 columns - attached in series and connected to a Shodex RI71 refractive index detector. The average molecular weights of polymers were determined from a calibration curve established using polystyrene (PS) standards.

\subsection{FTIR spectroscopic analysis}

2.3.1. FTIR spectroscopic analysis of polymerization reactions

FTIR spectra of the samples were obtained using a BIORAD FTS-3000 spectrometer. The samples were coated on
Table 1

Material compositions

\begin{tabular}{lllc}
\hline $\begin{array}{l}\text { Material } \\
\text { designation }\end{array}$ & $\begin{array}{l}\text { Content of FPUA } \\
\text { oligomer (wt\%) }\end{array}$ & $\begin{array}{l}\text { Content of } \\
\text { TPGDA (wt\%) }\end{array}$ & $\begin{array}{l}\text { Fluorine } \\
\text { wt\% }\end{array}$ \\
\hline TPGDA & 0 & 100 & 0 \\
M-25 & 25 & 75 & 17.1 \\
M-50 & 50 & 50 & 23.4 \\
M-75 & 75 & 25 & 26.7 \\
M-100 & 100 & 0 & 28.7 \\
H-25 & 25 & 75 & 18.5 \\
H-50 & 50 & 50 & 26.0 \\
H-75 & 75 & 25 & 30.1 \\
H-100 & 100 & 0 & 32.8 \\
\hline
\end{tabular}

"M-type FPUA oligomer: MDI/PFDDOL/HEMA $=2 / 1 / 2$

H-type FPUA oligomer: HDI/PFDDOL/HEMA $=2 / 1 / 2$.

$\mathrm{CaF}_{2}$ and 64 scans were obtained over the range from 4000 to $1000 \mathrm{~cm}^{-1}$ at a resolution of $2 \mathrm{~cm}^{-1}$.

\subsubsection{ATR-FTIR spectroscopic analysis of UV-cured films}

ATR-FTIR spectra of samples were obtained using a Perkin-Elmer Spectrum100 FTIR spectrometer. The spectra were obtained from 16 scans over the range from 4000 to $700 \mathrm{~cm}^{-1}$ at a resolution of $4 \mathrm{~cm}^{-1}$. The urethane carbonyl stretching region was deconvoluted using the Gaussian function to obtain the area under each signal for the various types of carbonyl group.

\subsubsection{Electron spectroscopy for chemical analysis (ESCA)}

ESCA spectra were obtained using an MT-500 spectrometer (VG MICROTECH, UK) equipped with a Mg K $\alpha$ source. High-resolution spectra were obtained at a take-off angle of $45^{\circ}$ for each element. All data analyses were accomplished using VGX900x software. Binding energies were referenced to the $\mathrm{C}-\mathrm{H}$ level at $285.0 \mathrm{eV}$.

\subsubsection{Thermal properties}

Thermal analysis was performed using a TA Instruments DSC 2010 and its built-in software. The samples

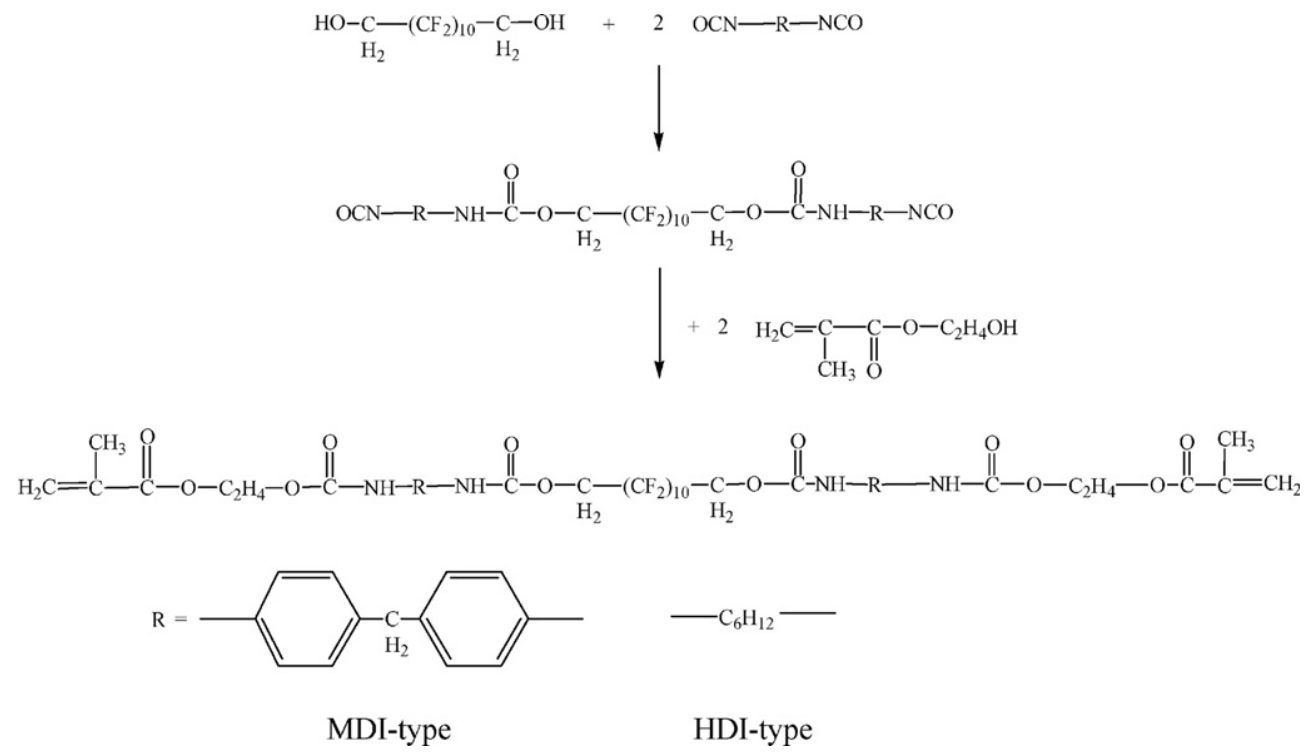

Scheme 1. Reaction scheme for the synthesis of MDI-type and HDI-type FPUA oligomers. 
(ca. $10 \mathrm{mg}$ ) were scanned from -100 to $+200{ }^{\circ} \mathrm{C}$ at a heating rate of $10^{\circ} \mathrm{C} \mathrm{min}^{-1}$ under a nitrogen purge. After reaching $200{ }^{\circ} \mathrm{C}$, the samples were rapidly cooled to $-100{ }^{\circ} \mathrm{C}$ and then a second scan to $200{ }^{\circ} \mathrm{C}$ was recorded at a heating rate of $10^{\circ} \mathrm{C} \mathrm{min}^{-1}$. The degradation temperature $\left(T_{\mathrm{d}}\right)$ was determined the temperature at which the residual weight of the samples became $95 \%$ of the original weight. The samples (ca. $10 \mathrm{mg}$ ) were scanned from 100 to $800{ }^{\circ} \mathrm{C}$ at a heating rate of $10^{\circ} \mathrm{C} \mathrm{min}^{-1}$ under a nitrogen purge.

\subsubsection{Mechanical properties}

Films were cut into dumbbell shapes (according to ASTMD-1457) that were 14-mm long and 5- and 16-mm wide at the narrow and gripping sections, respectively. The tensile strengths and elongations were determined at an extension rate of $5 \mathrm{~mm} \mathrm{~min}^{-1}$ (sample number: $n=5$ ) using a PT-1066 universal tensile testing instrument (Tien Shiang, Ltd., Taiwan).

\subsubsection{Transmission electron microscopy (TEM) observations}

The samples were microtomed to form sections that were ca. $900 \AA$ thick. The ultrathin cross-sections were placed on grids with an inert carbon support and then observed using a JEOL JEM-1230 TEM operated at $100 \mathrm{kV}$.

\subsubsection{Contact angle measurements}

The contact angles of water and ethylene glycol on the air-side surface of the prepared films were measured at room temperature using a contact angle meter (First $10 \AA$ A. FTA-125). Initial drops (ca. $5 \mu \mathrm{L}$ ) were deposited on the film surface employing a tight syringe, which was positioned $0.5 \mathrm{~mm}$ above the film surface. The volume of the drop was sequentially increased and decreased slowly by adding and withdrawing the liquid using the syringe. Direct measurements of the advancing contact angle, which reflects the hydrophobic character of the surface, and the receding contact angle, which is a measure of the relative hydrophilic character of the surface, were performed on both the left- and right-hand sides of each drop. To obtain reproducible results, care was taken to avoid vibration and distortion of the drop during changes in volume. More than five readings were obtained for each sample; average values and their standard deviation were calculated.

\subsubsection{Calculation of surface energy from contact angles}

Although the surface energy cannot be measured directly, a number of indirect methods for determining its value have been proposed in the literature. In this study, geometric-mean approximations were employed to obtain the dispersive and non-dispersive contributions to the total surface energy.

\subsubsection{Geometric-mean equation}

According to Owens and Wendt, the surface energy of a given solid can be determined using the following equation applied to two liquids [41]:

$(1+\cos \theta) \gamma_{l}=2\left(\gamma_{s}^{\mathrm{d}} \gamma_{l}^{\mathrm{d}}\right)^{1 / 2}+2\left(\gamma_{\mathrm{s}}^{\mathrm{nd}} \gamma_{1}^{\text {nd }}\right)^{1 / 2}$ where $\gamma_{s}$ and $\gamma_{1}$ are the surface free energies of the solid and pure liquid, respectively. The superscripts " $\mathrm{d}$ " and "nd" represent the dispersive and non-dispersive contributions to the total surface energy, respectively. The contact angle, $\theta$, in Eq. (1) was obtained from the following equation, which was proposed by Pinnau et al. [42]:

$\theta=\cos ^{-1}\left(\frac{\cos \theta_{\mathrm{a}}+\cos \theta_{\mathrm{r}}}{2}\right)$

where $\theta_{\mathrm{a}}$ and $\theta_{\mathrm{r}}$ are the advancing and receding contact angles, respectively.

By measuring the contact angles of two liquids on a film surface, two simultaneous equations will be obtained for Eq. (1); they are readily solved for $\gamma_{s}{ }^{d}$ and $\gamma_{s}{ }^{\text {nd }}$. Consequently, by assuming linear additivity of the intermolecular forces (i.e., the dispersive and non-dispersive forces), the sum of the two components, $\gamma_{\mathrm{s}}{ }^{\mathrm{d}}$ and $\gamma_{\mathrm{s}}{ }^{\text {nd }}$, should provide an estimated value of the total surface free energy, $\gamma_{s}$. Owens and Wendt employed water and methylene iodide as their test liquids [41], but other liquid pairs have been proposed in the literature. In this study, water $\left(\gamma_{1}\right.$ $=72.8 \mathrm{~mJ} \mathrm{~m}^{-2} ; \quad \gamma_{1}^{\mathrm{d}}=21.8 \mathrm{~mJ} \mathrm{~m}^{-2} ; \quad \gamma_{1}^{\text {nd }}=51 \mathrm{~mJ} \mathrm{~m}^{-2}$ ) and ethylene glycol $\left(\gamma_{1}=48 \mathrm{~mJ} \mathrm{~m}^{-2} ; \gamma_{1}^{\mathrm{d}}=29 \mathrm{~mJ} \mathrm{~m}^{-2} ; \gamma_{1}^{\text {nd }}=\right.$ $19 \mathrm{~mJ} \mathrm{~m}^{-2}$ ) were used.

\subsubsection{Relative index of platelet adhesion [43-47]}

The blood compatibility was evaluated by measuring the in vitro platelet adhesion using the following method. First, the polymer solution was cast onto the interior of a test tube to uniform thickness using a rotator and photopolymerized for $100 \mathrm{~s}$ using a flood UV exposure system equipped with a 350-W mercury lamp having an intensity at $365 \mathrm{~nm}$ of $330 \mathrm{~mJ} \mathrm{~cm}{ }^{-2}$. The coated tube and a blank tube were immersed in $0.9 \mathrm{~N} \mathrm{NaCl}$ solution overnight. Prior to testing, water on the surface was removed using a dry lens cleaning paper. Heparinized whole blood $\left(1.5 \mathrm{~cm}^{3}\right)$ was added to each tube. The tubes were shaken at $120 \mathrm{rpm}$ in a water bath maintained at $37^{\circ} \mathrm{C}$. After $1 \mathrm{~h}$, the blood was removed, diluted, and counted using a platelet counter. The relative index of platelet adhesion (RIPA) is defined as the ratio of the number of platelets adhering to the surface of the test sample to the number of platelets adhering to the glass:

$\operatorname{RIPA}=\frac{\left(N_{\mathrm{w}}-N_{\mathrm{p}}\right)}{\left(N_{\mathrm{w}}-N_{\mathrm{g}}\right)}$

where $N_{\mathrm{w}}, N_{\mathrm{p}}$, and $N_{\mathrm{g}}$ are the number of platelets in the whole blood, the number of platelets in the coated tube, and the number of platelets in the blank glass tube, respectively. A lower value of the RIPA indicates improved blood compatibility.

\section{Results and discussion}

\subsection{GPC analysis}

The number-average molecular weight of the MDI- and HDI-type FPUA oligomers were $4.6 \times 10^{3}$ and $3.6 \times 10^{3}$, respectively; the polydispersities were 1.39 and 1.17, respectively. 


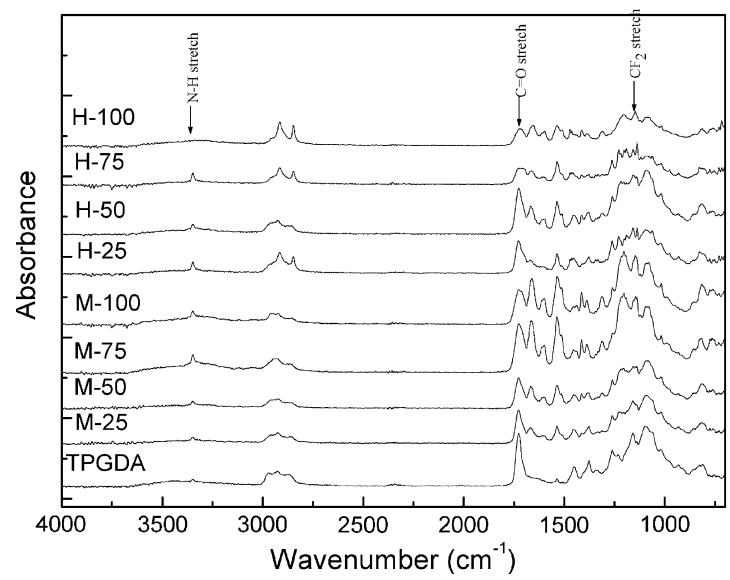

Fig. 1. ATR-FTIR absorption spectra of the FPUAs.

\subsection{FTIR spectroscopic analysis}

Fig. 1 displays the FTIR spectra of the FPUAs. The urethane carbonyl and $\mathrm{NH}$ stretching vibrations appear in the ranges $1695-1730$ and $3300-3500 \mathrm{~cm}^{-1}$, respectively. The band at $1180 \mathrm{~cm}^{-1}\left(\mathrm{CF}_{2}\right.$ stretching) indicates the presence of fluorocarbon chains in these FPUAs. As expected, the intensity of the $\mathrm{CF}_{2}$ absorption peak depended on the concentration of fluorine atoms. Fig. 2 presents expanded views of the amide and carbonyl stretching regions of these FTIR spectra. In the amide region (Fig. 2a), the hydrogen-bonded $\mathrm{NH}$ stretching vibrations appeared at ca. $3347 \mathrm{~cm}^{-1}$, while the free $\mathrm{NH}$ stretching bands appeared weakly at ca. $3450 \mathrm{~cm}^{-1}$; for the $\mathrm{H}-100$ sample, these vibrations occurred at ca. 3303 and ca. $3347 \mathrm{~cm}^{-1}$, respectively. Pimental and Sederholm [48] suggested that a linear relationship should exist between the length of the hydrogen bond (R) and the frequency shift $(\Delta v)$ of the hydrogen-bonded $\mathrm{NH}$ vibration, as expressed in Eq. (4):

$$
R=3.21-\Delta v /\left(0.548 \times 10^{3}\right)
$$

Thus, the hydrogen bonds of the $\mathrm{H}-100$ sample had an average length of $2.94 \AA$, while those of the other samples were $3.02 \AA$. Note that shorter hydrogen bonds are generally stronger. In the carbonyl stretching region (Fig. 2b), the signals of the hydrogen-bonded and free carbonyl groups appeared at ca. 1703 and ca. $1725 \mathrm{~cm}^{-1}$, respectively [49]. As indicated in Table 2, we deconvoluted the urethane carbonyl stretching region, using the Gaussian function, to obtain the area of each type of carbonyl group. In both series, the fraction of hydrogen-bonded carbonyl groups increased upon increasing the content of FPUA oligomer. Because the concentration of FPUA oligomers and the concentration of urethane groups both increased in the polymers, the extent of hydrogen bonding also increased in the polymer.

\subsection{Differential scanning calorimetry}

Table 3 summarizes their glass transition temperatures $\left(T_{\mathrm{g}}\right)$. We observed that TPGDA had a lower glass transition temperature $\left(T_{\mathrm{g}} ; 41.1^{\circ} \mathrm{C}\right)$ than both $\mathrm{M}-100\left(71.2^{\circ} \mathrm{C}\right)$ in the MDI series and $\mathrm{H}-100\left(65.8^{\circ} \mathrm{C}\right)$ in the HDI series. The values of $T_{\mathrm{g}}$ of both of the FPUAs increased upon increasing the content of FPUA oligomer, presumably because the high rigidity of the $\mathrm{CF}_{2}$ chain reduced the segment
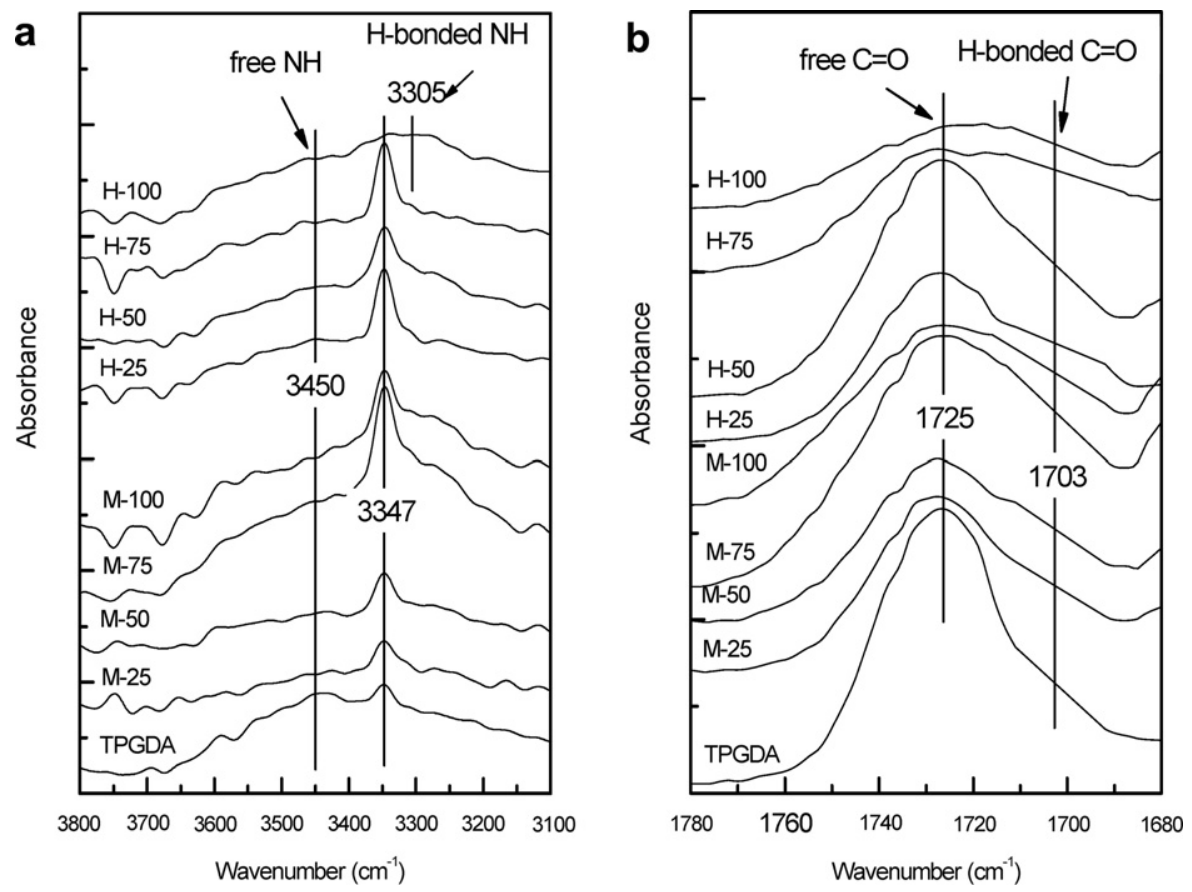

Fig. 2. Partial ATR-FTIR absorption spectra of the FPUAs: (a) $\mathrm{NH}$ and (b) $\mathrm{C}=\mathrm{O}$ stretching regions. 
Table 2

Deconvolution of the intensities of urethane carbonyl groups in IR spectra

\begin{tabular}{ll}
\hline Material & Hydrogen-bonded/free $C=0$ \\
\hline TPGDA & 0.18 \\
M-25 & 0.32 \\
M-50 & 0.40 \\
M-75 & 0.79 \\
M-100 & 0.90 \\
H-25 & 0.44 \\
H-50 & 0.55 \\
H-75 & 0.87 \\
H-100 & 0.94 \\
\hline
\end{tabular}

Table 3

Thermal analytical data and mechanical properties

\begin{tabular}{llllr}
\hline Material & $\begin{array}{l}T_{\mathrm{g}} \\
\left({ }^{\circ} \mathrm{C}\right)\end{array}$ & $\begin{array}{l}T_{\mathrm{d}} \\
\left({ }^{\circ} \mathrm{C}\right)\end{array}$ & \multicolumn{1}{l}{$\begin{array}{l}\text { Tensile strength } \\
(\mathrm{MPa})\end{array}$} & $\begin{array}{l}\text { Elongation } \\
(\%)\end{array}$ \\
\hline $\begin{array}{l}\text { TPGDAUV } \\
\quad \text { curing }\end{array}$ & 41.1 & 316.2 & $14.7 \pm 2.1$ & $5.8 \pm 0.2$ \\
M-25 & & & & $7.1 \pm 0.1$ \\
M-50 & 47.2 & 222.6 & $12.4 \pm 1.3$ & $8.4 \pm 0.5$ \\
M-75 & 54.8 & 214.8 & $11.7 \pm 1.5$ & $9.2 \pm 0.3$ \\
M-100 & 66.3 & 205.2 & $10.6 \pm 0.8$ & $11.1 \pm 1.1$ \\
H-25 & 71.2 & 195.1 & $8.6 \pm 1.2$ & $6.7 \pm 1.2$ \\
H-50 & 45.4 & 226.6 & $13.9 \pm 1.2$ & $8.8 \pm 0.7$ \\
H-75 & 53.7 & 213.1 & $12.8 \pm 1.8$ & $9.3 \pm 1.3$ \\
H-100 & 58.3 & 209.4 & $11.5 \pm 1.1$ & $12.4 \pm 1.7$ \\
\hline
\end{tabular}

mobility and increasing hydrogen bonding. We suggest that the increases in the concentration of FPUA oligomers, the concentration of urethane groups, and the extent of hydrogen bonding in the polymer all contributed to the increase in the value of $T_{\mathrm{g}}$ [50,51]. From a comparison of the MDI and HDI series, we found that the polymers in the MDI series had higher values of $T_{\mathrm{g}}$ than those in the HDI series. We attribute this result to the aromatic components of MDI reducing the segment mobility.

\subsection{Thermogravimetric analysis}

Figs. 3 and 4 display thermogravimetric analysis (TGA) and differential thermogravimetry (DTG) curves of the FPUAs; Table 3 summarizes their degradation temperatures. We observed that TPGDA exhibited a higher degradation temperature than did the other samples in both series. The TGA curve of the FPUA sample has two distinct regions of weight loss, implying that two-stage degradation occurred in this sample. Previous reports [52-54] of PU degradation suggest that initial degradation (Stage 1) results from decomposition of the urethane segments; the procedures occurring during Stage 2 are somewhat more inconclusive. The values of $T_{\mathrm{d}}$ for both of the FPUAs decreased upon increasing the content of FPUA oligomer, presumably because the good phase segregation between the PFDDOL and PUA's hard segments resulted in poor thermal stability. In addition, the char yield of the FPUAs increased upon increasing the fluorine content. We attribute these findings to the fluorinated materials undergoing thermal degradation with the release of HF, which reacts with highly reac- tive $\mathrm{H}$ and $\mathrm{HO}$ radicals in the flame, resulting in an inactive molecule and a $\mathrm{F}$ radical. The $\mathrm{F}$ radical has a much lower energy than either the $\mathrm{H}$ or $\mathrm{HO}$ species; therefore, it has a much lower potential for propagating the radical oxidation reaction that characterizes the burning process. This phenomenon increases the sample's degradation temperature and char yield during Stage 2 [55].

\subsection{Mechanical properties}

Table 3 displays the mechanical properties of the FPUAs. An increasing content of TPGDA led to a significant increase in the tensile strength and to a decrease in the elongation at break of the FPUA. We attribute this result to TPGDA having highly crosslinked networks. Comparing the MDI and HDI series of FPUAs, we find that the samples in the HDI series had higher tensile strength, presumably because they underwent stronger hydrogen bonding than did the samples in the MDI series (as described above). This hydrogen bonding improved the degree of microphase separation. Consequently, the tensile strength was enhanced [56].

\subsection{Transmission electron microscopy observations}

This result could be attributed to the bulk morphologies of the MDI and HDI series of FPUAs, as demonstrated in Fig. 5. The TEM images reveal dark regions for the hard phase domain of FPUA and white regions for the TPGDA phase. We found that the fluorinated poly(urethane-acrylate) oligomer aggregation in the FPUAs, presumably because the TPGDA and the fluorinated oligomer were incompatible, leading to aggregation of the fluorinated oligomer. Increasing the content of the fluorinated poly(urethane-acrylate) oligomer resulted in its more even distribution in the FPUAs; in other words, the phase separation increased. Comparing the MDI and HDI series, we observed that the HDI-type oligomer was more highly compatible with TPGDA than was the MDI-type FPUA oligomer. This result suggested that the greater extent of hydrogen bonding of the HDI series caused the fluorinated oligomer to disperse into the FPUAs to a greater extent.

\subsection{Electron spectroscopy for chemical analysis}

Table 4 displays the ESCA results for the surface element composition ratios of the FPUAs, in addition to the bulk atomic ratios calculated from the stoichiometric values of the reactants. ESCA measurement revealed the presence of fluorine atoms in the FPUAs, strongly suggesting the presence of fluorine-substituted chains on the film surface. The contents of nitrogen and fluorine atoms at surface represent the amounts of the hard block phase of poly(urethane-acrylate) and the fluorinated chains, respectively. For the FPUAs, the surface nitrogen-to-carbon $(\mathrm{N} / \mathrm{C})$ and fluorine-to-carbon $(\mathrm{F} / \mathrm{C})$ atomic ratios increased upon increasing the content of fluorinated poly(urethane-acrylate) oligomers. For the MDI and HDI series, the surface-to-bulk ratios of the nitrogen and fluo- 

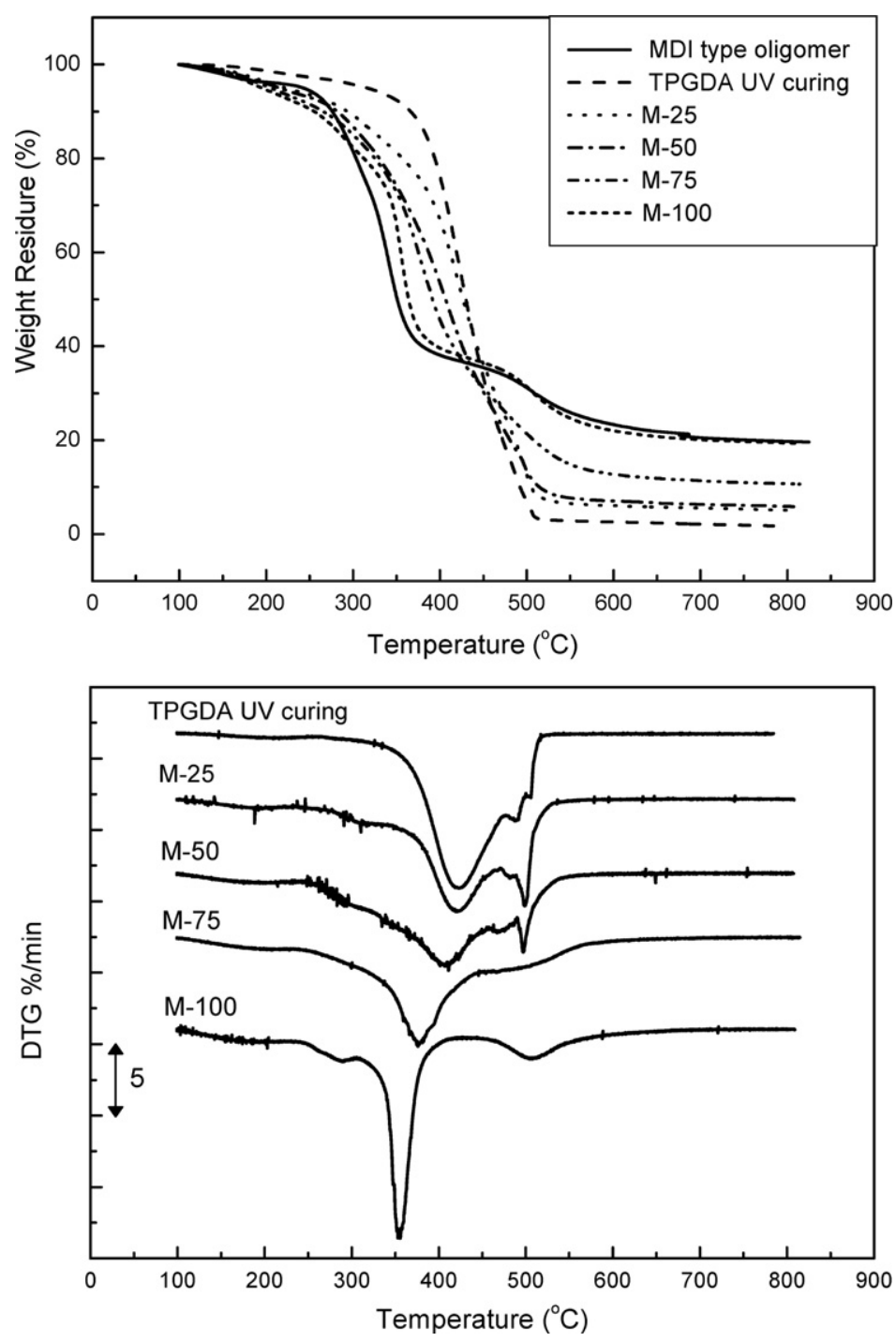

Fig. 3. TGA and DTG curves of the MDI-type FPUAs.

rine atoms decreased upon increasing the content of the fluorinated poly(urethane-acrylate) oligomers. This result suggested that the polymer exhibited a degree of higher phase separation [23]. This observation is consistent with our TEM data.

\subsection{Contact angle studies}

The contact angles of water and ethylene glycol were measured to determine the relative wettabilities of the film surfaces; Table 5 summarizes the results. Both the advancing and receding contact angles increased upon increasing the FPUA oligomer content; i.e., the surfaces of the FPUAs became more hydrophobic. We attribute this result to the presence of hydrophobic tail-like fluorine-substituted chains on the surfaces of the FPUAs. Fig. 6 displays the total surface energies of the FPUAs. We observe that TPGDA had a higher surface energy $\left(\gamma_{s} ; 38.9 \mathrm{~mJ} \mathrm{~m}^{-2}\right)$ than did either $\mathrm{M}-100\left(19.1 \mathrm{~mJ} \mathrm{~m}^{-2}\right)$ in the MDI series or $\mathrm{H}-100\left(22.7 \mathrm{~mJ} \mathrm{~m}^{-2}\right)$ in the HDI series. When comparing the MDI and HDI series, we find that the samples in the HDI series had low surface energies because of phase separation. Presumably, hydrogen bonding led to a higher degree of phase separation as a result of the formation of non-polar PFDDOL domains and polar (HEMA and urethane hard segment) domains of the FPUA [57]. These results suggest that the low total surface energy is due to the $\mathrm{CF}_{2}$ groups being presented on the outermost surface of the film.

\subsection{Relative index of platelet adhesion}

The RIPA value reflects the number of blood platelets adhered onto a sample, relative to those on a blank glass tube, when it comes into contact with blood. Low values 

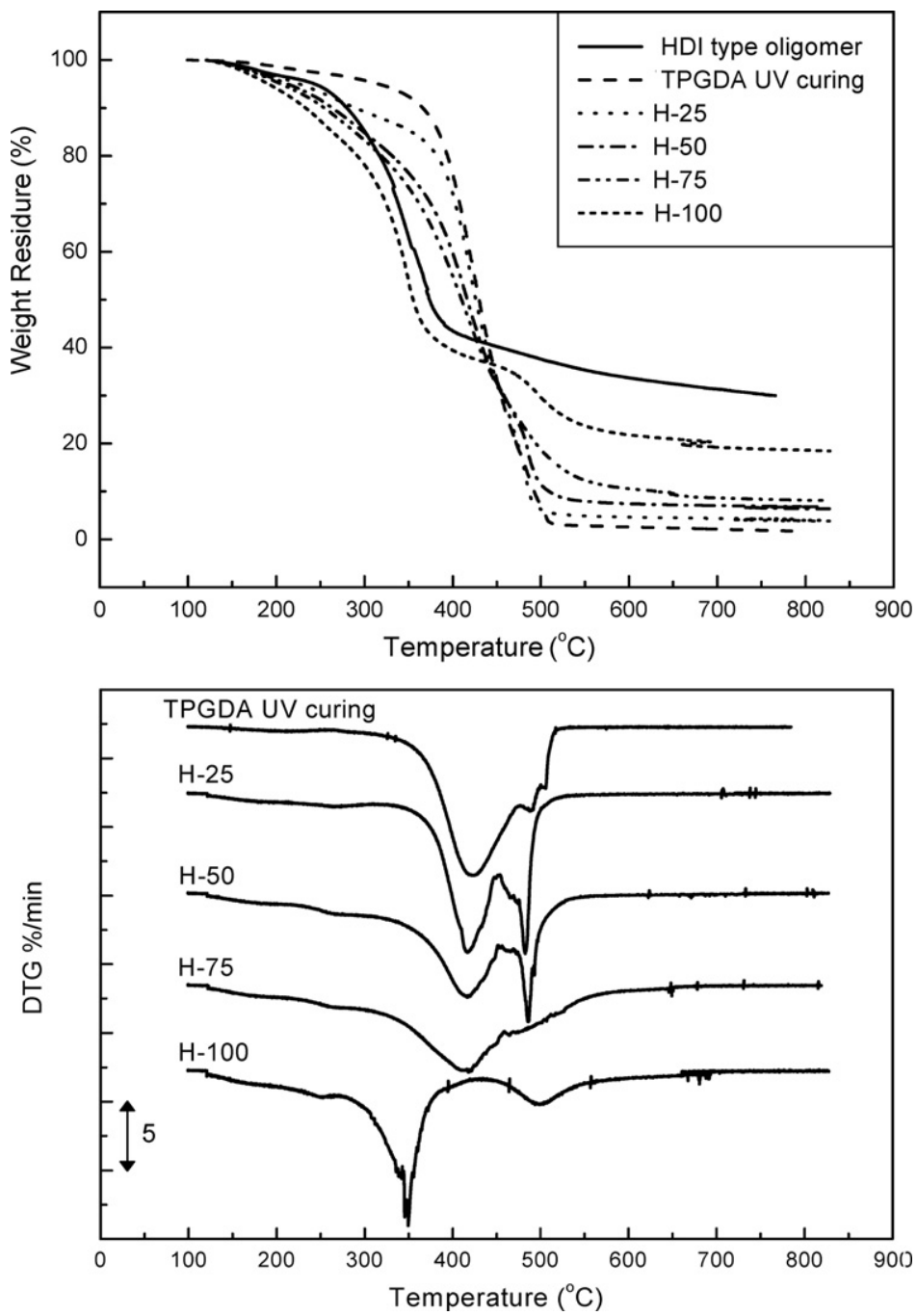

Fig. 4. TGA and DTG curves of the HDI-type FPUAs.

of the RIPA mean that fewer platelets adhere onto a sample; i.e., thrombosis is less likely to occur or, in other words, the material has better blood compatibility. There are many factors that affect blood adhesion. The microphase separation resulting from the hydrophilic/hydrophobic nature of a material's surface is one factor determining its blood compatibility, but other basic surface properties including the surface roughness, free energy, electric charge, and polarization distribution - also can exert their effects $[10,11,58]$.

The RIPA values of the FPUAs are listed in Table 5. The RIPA value of the HDI-type fluorinated poly(urethaneacrylate) reached as low as 0.13 . The RIPA values of both FPUAs decreased upon increasing the FPUA oligomer content. Moreover, the greater the number of fluorine atoms on the surface, the more thromboresistant the material, suggesting that a higher fluorocarbon chain content significantly reduced the degree of platelet adhesion and platelet activation on the polyurethane surface $[26,32,59]$. In addition, the presence of hydrogen bonding improved the phase separation at a high FPUA oligomer content in the HDI-type system, resulting in low surface energies and good blood compatibilities. This finding suggests that the morphological change caused by microphase separation led to a decrease in the degree of platelet adhesion, presumably because the low polarity of the $\mathrm{CF}_{2}$ units in the FPUAs decreased the total surface energy of the resultant polyurethanes [32]. Several investigators have reported that manipulating the surface energy of a polymeric substrate allows improvements to be made in its biocompatibility and blood compatibility $[19,20]$. For instance, Vogler et al. [60] found that hydrophobic surfaces displayed relatively lower levels of coagulation activation than did hydrophilic surfaces. Another study demonstrated that the presence of fluorocarbon groups in polyurethanes resulted in polymers that were less thrombogenic; it was suggested that the low surface energies of fluorine atoms 

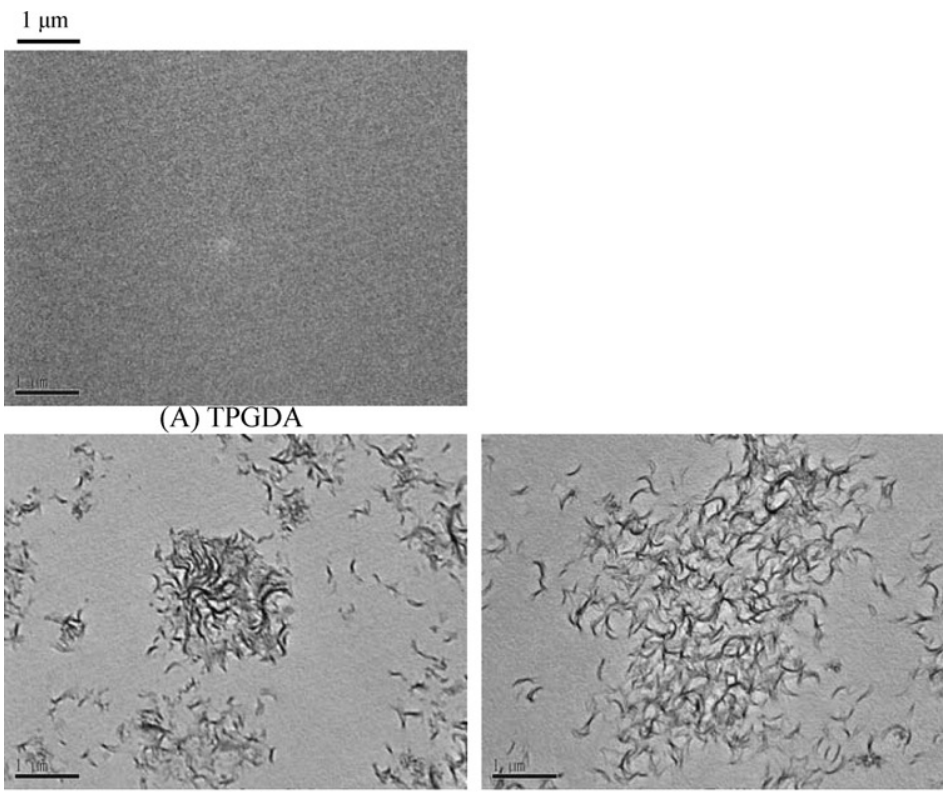

(B) $\mathrm{M}-25$

(F) $\mathrm{H}-25$

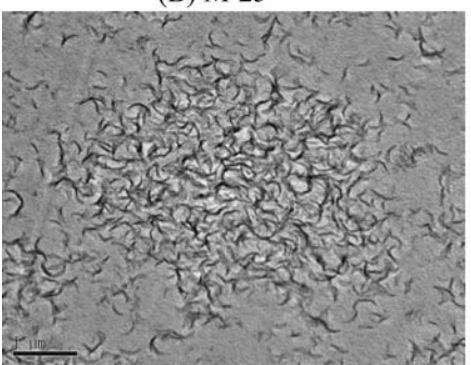

(C) $\mathrm{M}-50$
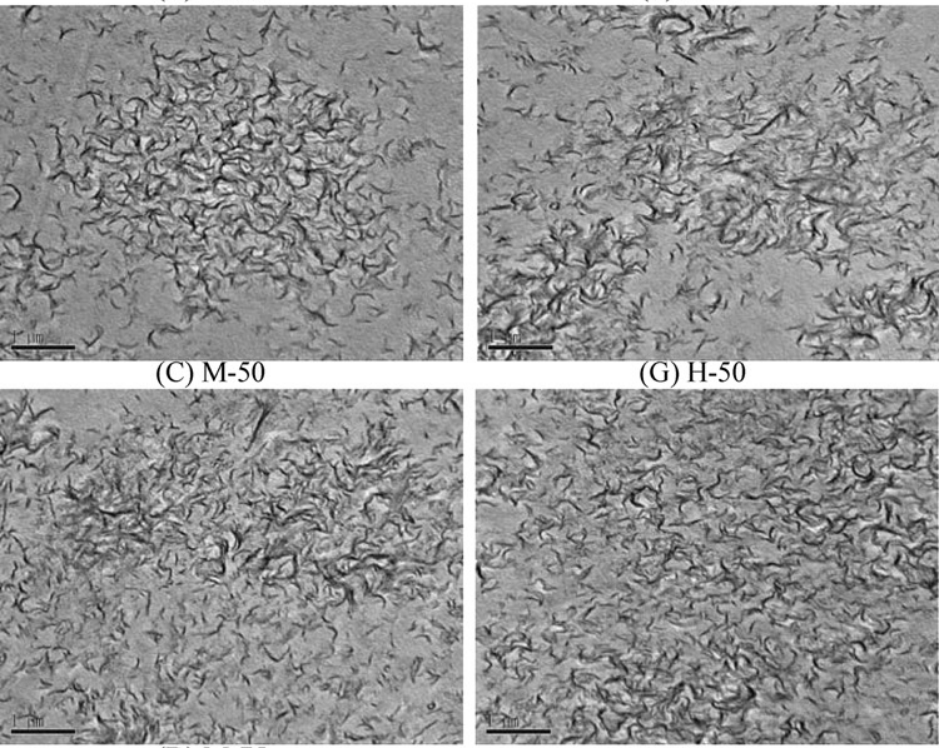

(D) $\mathrm{M}-75$

(H) $\mathrm{H}-75$

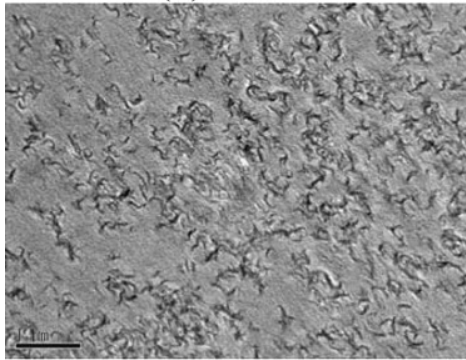

(E) $\mathrm{M}-100$

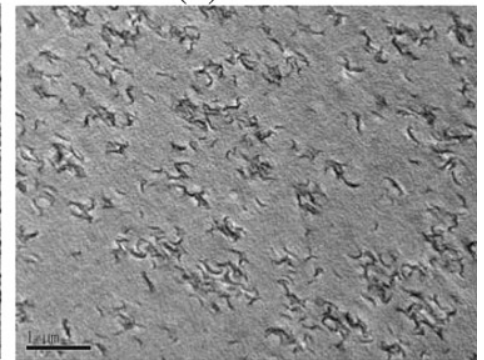

(I) $\mathrm{H}-100$

Fig. 5. TEM images of the FPUAs.

caused them to become concentrated preferentially at the surface of the polymer, reducing the degrees of pro- tein adsorption, platelet adhesion, and platelet activation [59]. 
Table 4

ESCA analysis

\begin{tabular}{|c|c|c|c|c|c|c|c|c|c|}
\hline \multirow[t]{2}{*}{ Material } & \multicolumn{3}{|l|}{$\mathrm{N} / \mathrm{C}$} & \multicolumn{3}{|l|}{$\mathrm{O} / \mathrm{C}$} & \multicolumn{3}{|l|}{$\mathrm{F} / \mathrm{C}$} \\
\hline & Bulk & Surface & Surface/bulk & Bulk & Surface & Surface/bulk & Bulk & Surface & Surface/bulk \\
\hline TPGDA & - & - & - & 0.533 & 0.576 & 1.08 & - & - & - \\
\hline M-25 & 0.047 & 0.044 & 0.94 & 0.404 & 0.416 & 1.03 & 0.32 & 0.285 & 0.89 \\
\hline$M-50$ & 0.068 & 0.055 & 0.81 & 0.348 & 0.327 & 0.94 & 0.459 & 0.326 & 0.71 \\
\hline M-75 & 0.079 & 0.061 & 0.77 & 0.316 & 0.303 & 0.96 & 0.537 & 0.338 & 0.63 \\
\hline M-100 & 0.086 & 0.056 & 0.65 & 0.296 & 0.275 & 0.93 & 0.586 & 0.299 & 0.51 \\
\hline $\mathrm{H}-25$ & 0.055 & 0.048 & 0.87 & 0.471 & 0.466 & 0.99 & 0.373 & 0.272 & 0.73 \\
\hline $\mathrm{H}-50$ & 0.085 & 0.065 & 0.76 & 0.436 & 0.445 & 1.02 & 0.576 & 0.409 & 0.71 \\
\hline $\mathrm{H}-75$ & 0.104 & 0.067 & 0.64 & 0.415 & 0.403 & 0.97 & 0.704 & 0.401 & 0.57 \\
\hline H-100 & 0.117 & 0.066 & 0.56 & 0.4 & 0.452 & 1.13 & 0.792 & 0.372 & 0.47 \\
\hline
\end{tabular}

Table 5

Contact angle, surface tension, and RIPA values of FPUAs

\begin{tabular}{|c|c|c|c|c|c|c|c|c|}
\hline \multirow[t]{2}{*}{ Material } & \multicolumn{2}{|l|}{ Water } & \multicolumn{2}{|c|}{ Ethylene glycol } & \multicolumn{3}{|c|}{ Geometric-mean equation $\left(\mathrm{mJ} \mathrm{m}^{-2}\right)$} & \multirow[t]{2}{*}{ RIPA } \\
\hline & $\theta_{\mathrm{r}}$ & $\theta_{\mathrm{r}}$ & $\theta_{\mathrm{r}}$ & $\theta_{\mathrm{r}}$ & $\gamma_{s}^{\text {nd }}$ & $\gamma_{\mathrm{s}}^{\mathrm{d}}$ & $\gamma_{s}$ & \\
\hline TPGDA & $68.7 \pm 0.4$ & $58.8 \pm 0.6$ & $55.2 \pm 2.3$ & $52.2 \pm 2.5$ & $6.0 \pm 0.3$ & $32.9 \pm 1.5$ & $38.9 \pm 1.8$ & $0.81 \pm 0.14$ \\
\hline M-25 & $77.0 \pm 2.2$ & $72.4 \pm 1.6$ & $61.3 \pm 1.7$ & $55.5 \pm 1.2$ & $11.2 \pm 0.5$ & $18.1 \pm 0.7$ & $29.3 \pm 1.2$ & $0.58 \pm 0.09$ \\
\hline$M-50$ & $83.9 \pm 3.5$ & $79.3 \pm 1.7$ & $58.7 \pm 1.6$ & $55.5 \pm 1.4$ & $20.9 \pm 0.8$ & $8.1 \pm 0.2$ & $29.0 \pm 1.0$ & $0.41 \pm 0.05$ \\
\hline M-75 & $89.9 \pm 0.4$ & $87.1 \pm 1.3$ & $62.7 \pm 2.1$ & $59.2 \pm 1.9$ & $25.7 \pm 1.2$ & $3.1 \pm 0.1$ & $28.8 \pm 1.3$ & $0.29 \pm 0.06$ \\
\hline M-100 & $92.0 \pm 1.2$ & $89.1 \pm 1.2$ & $66.0 \pm 2.3$ & $61.0 \pm 1.5$ & $8.4 \pm 0.1$ & $10.7 \pm 0.1$ & $19.1 \pm 0.2$ & $0.16 \pm 0.03$ \\
\hline $\mathrm{H}-25$ & $83.7 \pm 1.3$ & $80.2 \pm 0.7$ & $59.3 \pm 0.4$ & $56.4 \pm 2.2$ & $20.4 \pm 0.7$ & $8.1 \pm 0.3$ & $28.5 \pm 1.0$ & $0.50 \pm 0.10$ \\
\hline $\mathrm{H}-50$ & $86.8 \pm 2.7$ & $85.6 \pm 2.2$ & $67.4 \pm 2.4$ & $63.1 \pm 1.9$ & $16.6 \pm 0.2$ & $7.7 \pm 0.1$ & $24.3 \pm 0.3$ & $0.38 \pm 0.09$ \\
\hline $\mathrm{H}-75$ & $85.9 \pm 2.3$ & $85.1 \pm 1.8$ & $70.8 \pm 0.3$ & $67.9 \pm 1.2$ & $11.3 \pm 0.7$ & $10.8 \pm 0.4$ & $22.1 \pm 1.1$ & $0.24 \pm 0.04$ \\
\hline $\mathrm{H}-100$ & $95.2 \pm 2.2$ & $92.5 \pm 1.5$ & $74.9 \pm 2.2$ & $66.6 \pm 2.8$ & $19.3 \pm 0.4$ & $3.4 \pm 0.1$ & $22.7 \pm 0.5$ & $0.13 \pm 0.02$ \\
\hline
\end{tabular}

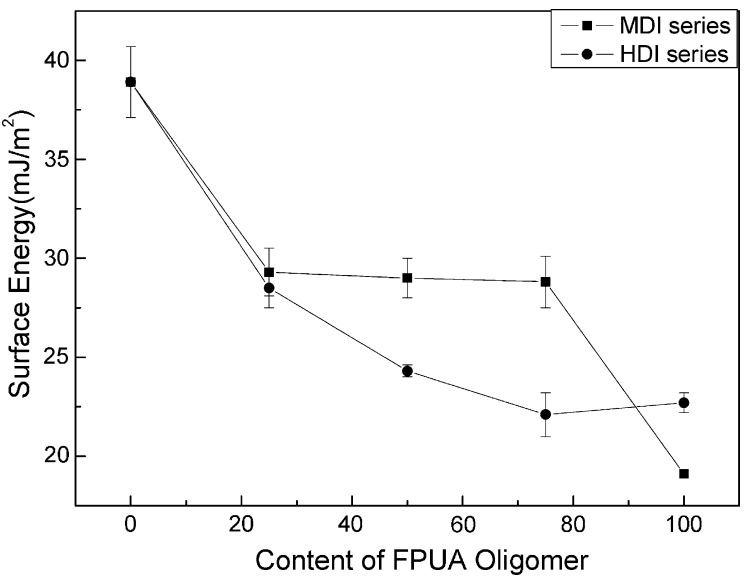

Fig. 6. Relationship between the surface energy and the weight percentage of FPUA oligomer:

\section{Conclusion}

In this study, we synthesized novel UV-curable FPUA polymers incorporating hydrophobic (PFDDOL) and hydrophilic (HEMA and urethane groups) domains. The oligomers reacted through photopolymerization to form highly crosslinked networks within minutes of UV irradiation; this procedure might be useful for coating the surfaces of materials (e.g., polyurethane artificial blood vessels or polyurethane ventricular assist devices) that come into contact with blood. The hydrophobic/hydrophilic domain structures exhibited microphase separation, which induced a low degree of platelet adhesion. In addition, the presence of hydrogen bonds improved the degree of phase separation at a high FPUA oligomer content, resulting in samples exhibiting low surface energies and good blood compatibilities. The values of the RIPA of the HDI-type UV-curable fluorinated poly(urethane-acrylate) reached as low as 0.13 .

\section{References}

[1] Ratner BD, Schoen FJ, Lemons JE. Biomaterials Science: An Introduction to Materials in Medicine. Boston: Academic Press; 2004.

[2] Nagaoka S, Mori Y, Tanzawa H, Kikuchi Y, Inagaki F, Yokota Y, et al. Trans ASAIO 1987;10:76.

[3] Kulik E, Ikada Y. J Biomed Mater Res 1996;30:295

[4] Morra M. J Biomater Sci, Polym Ed 2000;11:547.

[5] Okano T, Nishiyama S, Shinohara I, Akaike T, Sakurai Y, Kataoka K, et al. J Biomed Mater Res 1981;15:393.

[6] Yui N, Sanui K, Ogata N, Kataoka K, Okano T, Sakurai Y. J Biomed Mater Res 1986;20:929.

[7] King M, Zhang Z. Biomaterials 1994;15:621.

[8] Guidoin R, Sigot-Luirard MF. Biomaterials 1992;13:281.

[9] Huang B, Marios Y. Biomaterials 1992;13:209.

[10] Lin YH, Chou NK, Chen KF, Ho GH, Chang CH, Wang SS, et al. Polym Int 2007;56:1415.

[11] Lee PC, Chen LW, Lin JR, Hsieh KH, Huang LLH. Polym Int 1996;41:419.

[12] Grasel TG, Cooper SL. Biomaterials 1986;7:315.

[13] Huang SL, Chao MS, Ruaan RC, Lai JY. Eur Polym J 2000;36:285.

[14] Hergenrother RW, Wabers HD, Cooper SL. Biomaterials 1993;14:449.

[15] Schmidt JA, von Recum AF. Biomaterials 1991;12:385.

[16] Wall LA. Fluoropolymers. New York: Wiley-Interscience; 1972.

[17] Scheirs J, Burks S, Locaspi A. Trends Polym Sci 1995;3:74.

[18] Kim YS, Lee JS, Ji Q, McGrath JE. Polymer 2002;43:7161.

[19] Chapman TM, Marra KG. Macromolecules 1995;28:2081.

[20] Guerra RSD, Lelli L, Tonelli C, Trombetta T, Cascone MG, Taveri M, et al. J Mater Sci Mater Med 1994;5:452.

[21] Yoon SC, Ratner BD. Macromolecules 1986;19:1068. 
[22] Takakura T, Kato M, Yamabe M. Macromol Chem 1990;191:625.

[23] Yoon SC, Ratner BD. Macromolecules 1988;21:2392.

[24] Takahara NJ, Takamori K, Kajiyama T. In: Gebelein CG, Dunn RL, editors. Progress in Biomedical Polymers. New York: Plenum Press; 1990.

[25] Kajiyama T, Takahara A. J Biomater Appl 1991;6:42.

[26] Ho T, Wynne KJ. Macromolecules 1992;25:3521.

[27] Honeychuck RV, Ho T, Wynne KJ, Nissan RA. Chem Mater 1993;5:1299.

[28] Tang YW, Santerre JP, Labow RS, Taylor DG. J Biomed Mater Res 1997;35:371.

[29] Pizzoferrato A, Arciola CR, Cenni E, Ciapetti G, Sassi S. Biomaterials $1995 ; 16: 361$

[30] Chen KY, Kuo JF. Macromol Chem Phys 2001;201:2676.

[31] Wang LF, Wei YH. Colloids Surf B: Biointerfaces 2005;41:249.

[32] Burillo G, Ogawa T, Hwang JS. J Polym Sci, Part A: Polym Chem 1992;30:2159.

[33] Shen JY, Pan XY, Lim CH, Chan-Park MB, Zhu X, Beuerman RW. Biomacromolecules 2007:8:376.

[34] Ward JH, Bashir R, Peppas NA. J Biomed Mater Res 2001;56:351.

[35] Sangermano M, Bongiovanni R, Malucelli G, Priola A, Pollicino A, Recca A. J Appl Polym Sci 2003;89:1524.

[36] Sangermano M, Bongiovanni R, Priola A, Pospiech D. J Polym Sci Part A: Polym Chem 2005;43:4144

[37] Bongiovanni R, Sangermano M, Malucelli G, Priola A, Leonardi A, Ameduri B. J Polym Sci Part A: Polym Chem 2003;41:2890.

[38] Sangermano M, Bongiovanni R, Malucelli G, Priola A, Thomas RR, Medsker RE, et al. Polymer 2004;45:2133.
[39] Sangermano M, Bongiovanni R, Malucelli G, Priola A, Thomas RR, Kausch CM, et al. J Polym Sci Part A: Polym Chem 2006;44:6943.

[40] Lin YH, Chou NK, Chang CH, Wang SS, Chu SH, Hsieh KH. J Polym Sci Part A: Polym Chem 2007;45:3231.

[41] Owens DK, Wendt RC. J Appl Polym Sci 1969;13:1741.

[42] Pinnau I, Freeman BD. ACS Symposium Series 744. Washington DC: American Chemical Society; 2000.

[43] Woodhouse KA, Brash JL. Biomaterials 1992;13:1103.

[44] Mathew J, Liu SQ, Kodama M. Biomaterials 1993;14:57.

[45] William DF. Techniques of Biocompatibility Testing. Boca Raton, FL: CRC Press; 1986

[46] Elam JH, Nygren H. Biomaterials 1992;13:3.

[47] Haycox CL, Ratner BD. J Biomed Mater Res 1993;27:1181.

[48] Pimentel GC, Sederholm CH. J Chem Phys 1956;24:639.

[49] Yukiyasu K, Urban MW. Prog Org Coat 1999;35:247.

[50] Otts DB, Hendenreich E, Urban MW. Polymer 2005;46:8162.

[51] Krol P. Prog Mater Sci 2007;52:915.

[52] Petrovic S, Zavargo Z, Flynn JH, Macknight WJ. J Appl Polym Sci 1994;51:1087.

[53] Lin MF, Tsen WC, Shu YC, Chuang FS. J Appl Polym Sci 2001;79:881.

[54] Chuang FS, Tsen WC, Shu YC. Polym Degrad Stabil 2004;84:69.

[55] Bacaloglu R, Fisch M. Polym Degrad Stabil 1995;47:33.

[56] Hepburn C. Iran Polym J 1992;1:84.

[57] Yung LYL, Cooper SL. Biomaterials 1998;19:31.

[58] Okkema AZ, Visser SA. J Biomed Mater Res 1991;25:1371.

[59] Kashiwagi T, Ito Y, Imanishi Y. J Biomet Sci Polym Ed 1993;5:157.

[60] Vogler E, Graper J, Harper G, Sugg H, Lander L, Brittain W. J Biomed Mater Res 1995;29:1005. 